\title{
APLICACIÓN DE LA TECNOLOGÍA LÁSER EN LAS LESIONES DE GENITALES
}

\author{
Esther Díez Recio', Jesús Cuevas Santos², Pablo Boixeda de Miquel³, Eduardo Fonseca Capdevila 4 y \\ Esther de Eusebio Murillo'.
}

'Servicio de Dermatología. Hospital Universitario. Guadalajara.

${ }^{2}$ Servicio de Anatomía Patológica. Hospital Universitario. Guadalajara.

${ }^{3}$ Servicio de Dermatología. Hospital Ramón y Cajal. Madrid.

${ }^{4}$ Servicio de Dermatología. Hospital Universitario Juan Canalejo. A Coruña. España.

\begin{abstract}
Resumen.- El empleo del láser en urología ha presentado un avance significativo y en la actualidad es empleado en una gran variedad de patologías. El desarrollo de los diferentes tipos de láser, el empleo de diferentes tipos de longitudes de onda, los sistemas de fibra óptica, la precisión y la reducción del coste han hecho mejorar la tecnología del láser, y extender y potenciar sus indicaciones. Los diversos tipos de láser de los que disponemos en la actualidad, suponen una excelente alternativa terapéutica en el tratamiento de diversas patologías benignas, pre-malignas y malignas localizadas en los genitales, con excelentes resultados estéticos y funcionales, y con una reducida morbilidad.. El objetivo de esta trabajo es proporcionar las indicaciones clínicas más importantes y aplicaciones con el láser más novedosas en las lesiones genitales.
\end{abstract}

Palabras clave: Láser de $\mathrm{Nd}: Y A G$. Láser de $\mathrm{CO}_{2}$. Láser de colorante pulsado. Láser Q-switched. Lesiones genitales. Tratamiento. Revisión. Láser.

Summary.- The use of laser applications in urology has undergone significant advances and is now used in a wide variety of procedures. Improvements in types of lasers, the wavelength of energy used, optical fiber delivery systems, precision of laser applications and cost reduction have served to further improve laser technology and extend the potential applications. The different types of lasers available at the present time appear to be an alternative treatment modality with excellent cosmetic and functional results and low morbidity in the treatment of benign, pre-malignant and malignant lesions in the genital area. The objective of this article is to provide an update on the most important clinical and experimental advancements therapeutic applications of lasers in genital lesions.

Keywords: Nd:YAG laser. CO $\mathrm{CO}_{2}$. Pulsed dye laser. Q-switched. Genital lesions. Treatment. Review. Laser.

\section{INTRODUCCIÓN}

El láser es un sistema complejo de energía radiante en forma de fotones y ondas. La distancia entre las crestas de 2 ondas sucesivas determina su longitud de onda, el color de la luz visible y su posición dentro del espectro electromagnético. Dentro del espectro electromagnético, la emisión láser suele encontrarse entre la zona visible y el infrarrojo. Entre 400 y $700 \mathrm{~nm}$ se encuentra los picos de absorción de energía del agua, la hemoglobina y la melanina. Los efectos biológicos del láser dependen de la longitud de onda, lo que determina su absorción y su penetración, y de las características ópticas del tejido diana. La fototermólisis selectiva es la producción de lesiones térmicas selectivas en una estructura diana al administrar 
una energía suficiente, a una longitud de onda absorbida preferentemente por el tejido diana, durante un tiempo igual o inferior al de su relajación térmica. La fototermólisis puede realizarse mediante la vaporización del agua intra y extracelular para la ablación de la epidermis, como ocurre en el láser ablativos, de dióxido de carbono (CO2) y de Erbium:Ytrium Aluminium Garnet (Er:YAG). La destrucción selectiva de vasos sanguíneos puede realizarse mediante el láser de colorante, luz intensa polarizada (IPL) o láser de neodymiun-YAG (Nd-YAG). La destrucción de pigmentos mediante el láser de Alejandrita Q-switched o el NdYAG Q switched (a $1064 \mathrm{~nm}$ o desdoblado a $532 \mathrm{~nm}$ ) se produce por efecto fotoacústico (la concentración de altas energías en tiempos extremadamente cortos, a nivel de los nanosegundos, produce la fragmentación de las partículas pigmentadas que podrán ser fagocitadas por los macrófagos) (1).

La tecnología basada en empleo del láser ha experimentado en los últimos años un avance espectacular. Han aparecido muy diferentes tipos de láser, con indicaciones médicas determinadas por las características físicas de cada uno de ellos. Además, otros láseres más antiguos han sido modificados y mejorados, ampliándose su campo de acción.

\section{TIPOS DE LÁSER}

Comentaremos los tipos de láser que más se emplean en la patología de los genitales masculinos.

El láser ablativo más empleados es el láser de $\mathrm{CO}_{2}$. Emite una luz en el espectro infrarrojo con una longitud de onda de $10.600 \mathrm{~nm}$. Tras el impacto del haz se produce un área central de tejido destruido, que es la zona de evaporación del agua. Alrededor se forma una zona de necrosis térmica inespecífica (desnaturalización de proteínas) de aproximadamente $50 \mu \mathrm{m}$; es en esta zona donde se produce el sellado de los vasos pequeños, linfáticos y nervios. La zona más periférica es la del daño subletal o edema, que abarca hasta unos $250 \mathrm{\mu m}$. Por tanto, se debe tener en cuenta que la profundidad de la penetración final sobrepasa la profundidad de la zona vaporizada que es visible.

En cuanto a la técnica, debe considerarse 2 factores importantes, la potencia y el modo o duración del pulso (continuo o discontinuo o pulsado). La potencia dependerá de la lesión a tratar. La mayoría de las lesiones epidérmicas son fácilmente destruidas con una potencia de 3 a $8 \mathrm{~W}$, mientras que las más profundas pueden requerir $20 \mathrm{~W}$. Cuando el láser se usa en el "modo continuo", la conducción de calor provoca un daño térmico inespecífico en los 0.5-1 mm que rodean a la zona de impacto. La principal ventaja de esta zona extra de daño térmico es que los vasos sanguíneos mayores de $0.5 \mathrm{~mm}$ de diámetro pueden ser sellados, haciendo que la cirugía de láser de $\mathrm{CO}_{2}$ sea prácticamente incruenta. Desafortunadamente, el daño térmico también retrasa la curación de la herida y se asocia a un riesgo incrementado de cicatriz. Para reducir la zona de daño térmico inespecífico, la duración del pulso debe ser más corta que los 0.5-1 ms de relajación o en- friamiento de los 20-50 $\mu \mathrm{m}$ del tejido que rodea a la zona de impacto ("modo pulsado o superpulsado"). El láser de $\mathrm{CO}_{2}$ superpulsado emite un conjunto de pulsos muy cortos que tienen de 2 a 10 veces la potencia del láser continuo. Cada pulso individual tiene una duración menor de 0.5-1 ms. Para generar suficiente flujo de energía para evaporar el tejido, los pulsos deben ser emitidos a más de $1000 \mathrm{~Hz}$. La zona de daño térmico inespecífico es de 0.2-0.5 mm, algo menor que la causada por el láser continuo.

Se puede variar el diámetro del impacto trabajando con el haz enfocado o desenfocado. Para una misma potencia, la irradiación será mayor cuanto menos sea el diámetro de impacto, es decir, cuando el haz este "enfocado". Esta forma se utilizará para cortar y destruir el tejido. Si el haz está "desenfocado", el diámetro de impacto aumenta, y ésta será la forma que utilizaremos para vaporizar y coagular el tejido.

En general, para las lesiones epidérmicas se emplea un diámetro de impacto de $2 \mathrm{~mm}$ desenfocado, a una potencia de 5 a $15 \mathrm{w}$, en emisión continua o pulsátil, con tiempo de exposición de $0.3 \mathrm{~s}$ y de irradiación de 320 a $480 \mathrm{w} / \mathrm{cm}^{2}(2)$.

Las principales ventajas del láser de $\mathrm{CO}_{2}$ en el tratamiento de las lesiones en el área genital son: facilidad de manejo, rapidez de acción y control preciso de la sección tisular. Selectividad y especificidad sobre el daño tisular, ocasionando una destrucción muy localizada y segura, con un mínimo daño de los tejidos próximos. Tiene una aceptable capacidad de hemostasia de vasos hasta $0.5 \mathrm{~mm}$. Permite el tratamiento de múltiples lesiones, con una reducida morbilidad y muy buenos resultados estéticos y funcionales. No interfiere con el marcapasos, ni hay riesgos con los tratamientos anticoagulantes o hipotensores, por lo que es ideal para el tratamiento de enfermos cardiacos y en ancianos.

Entre sus inconvenientes se encuentran: es doloroso, debido al calentamiento que produce en el tejido, siendo necesario anestesiar la zona mediante infiltración local o bloqueo nervioso; el riesgo potencial de transmisión viral; los efectos carcinogénicos del humo y la falta de control histológico. Los efectos adversos son: cicatrices hipertróficas, alteración en la pigmentación, infecciones, hemorragias de pequeña cuantía, dolor intra o postoperatorio.

Respecto a la eficacia contrastada entre los procedimientos ablativos, parece que el láser de $\mathrm{CO}_{2}$ es más efectivo y posee mayor capacidad para causar adelgazamiento cutáneo que el láser de $\mathrm{Er}: Y A G$, aunque produce mayor hipopigmentación permanente. El uso secuencial de $\mathrm{CO}_{2}$ seguido de Er:YAG es un procedimiento menos agresivo que reduce el tiempo de curación, el eritema persistente, la cicatrización y otras complicaciones (3).

El láser de colorante pulsado (LCP) produce una fototermolisis selectiva con la hemoglobina intravascular. La luz del láser absorbida por la oxihemoglobina, se convierte en calor y daña el endotelio vascular produciendo trombosis y destrucción del vaso. Dentro de un gran número de aparatos de láser de colorante pulsado, cada cual más versátil, interesa ceñirnos a los siguientes parámetros y valores 
de oscilación: diámetro del haz del láser (5-10 mm), longitud de onda $(585-600 \mathrm{~nm})$, densidad de energía o fluencia $\left(7-15 \mathrm{~J} / \mathrm{cm}^{2}\right)$ y duración del pulso (desde 0.5 hasta 40 $\mathrm{ms})$. Algunos de los parámetros que pueden mejorar los resultados finales son la utilización de pulsos de duración de 0.5 a $1.5 \mathrm{~ms}$, longitudes de onda más altas $(600 \mathrm{~nm})$ o fluencias mayores. Aunque la absorción máxima se produce a $577 \mathrm{~nm}$, aumentando la longitud de onda se obtiene una menor absorción por la oxihemoglobina (compensada con un aumento de la energía administrada), pero una mayor penetración cutánea. Probablemente la longitud de onda más empleada hoy en día es $595 \mathrm{~nm}$. La duración del pulso se ha incrementado para tratar de coagular los vasos de mayor tamaño y para producir un calentamiento lento del vaso que permita reducir el efecto purpúrico tras el tratamiento. Entre los inconvenientes encontramos que, con pulsos largos, se requieren mayores fluencias para producir coagulación (podrían dañar la epidermis y la dermis perivascular a fluencias altas) y que los pulsos demasiados largos pueden no ser capaces de tratar los vasos dilatados de menor calibre. En cuanto al diámetro del haz, el uso de los aplicadores de gran diámetro permite tratamientos más rápidos, más uniformes y con mayor lesión vascular a menores fluencias (4).

En los lactantes y niños el tratamiento se inicia con fluencias bajas, pudiendo aumentar $0.5-1 \mathrm{~J} / \mathrm{cm}^{2}$ en cada sesión, en función de la respuesta y de los posibles efectos secundarios (5).

El tratamiento se tolera bien sin anestesia, aunque en los niños pequeños se puede precisar sedación.

En la actualidad es el tratamiento de elección en las malformaciones capilares.

Los inconvenientes de láseres de colorante pulsado son: la presencia de púrpura en la zona tratada y una penetrancia limitada que impide el tratamiento de las lesiones nodulares o en empedrado, las lesiones localizadas en profundidad, los vasos de mediano y gran calibre y las lesiones de color oscuro o violáceas (6). Además es necesario la realización de múltiples sesiones de tratamiento, lo cual prolonga en meses o años la asistencia a estos pacientes. Suelen ser necesarias más de 10 sesiones.

Los efectos secundarios son las ampollas, costras, hiperpigmentación, hipopigmentación, desarrollo de cicatrices atróficas o hipertróficas e infecciones.

Aquellos pacientes que no respondan al láser de colorante pulsado, pueden ser tratados con luz pulsada intensa (IPL). En la patología genital externa los más empleados son el láser de Nd:YAG y el láser de KTP (7). Las fluencias empleadas con mejores resultados se sitúan entre 18 y $24 \mathrm{~J} / \mathrm{cm}^{2}$, con duraciones del pulso entre $9-14$ ms. Se obtienen mejorías entre un $70-100 \%$ en el $70 \%$ de los pacientes. Estos aparatos permiten altas fluencias y la posibilidad de ajustar la duración del pulso al tiempo de relajación térmica de la estructura a destruir.

El láser KTP (potassium-titanyl-phospate) tiene una longitud de onda de $532 \mathrm{~nm}$ y duración de pulso entre 1 y
50 ms, aunque penetra menos y tiene una mayor absorción por la melanina.

Otros láseres de onda continua son el de argón; el vapor de cobre (que emite una luz de $578 \mathrm{~nm}$ ) y Kriptón (longitud de onda de $568 \mathrm{~nm}$ ) y el láser Q-switched $\mathrm{Nd}$ : YAG con una longitud de onda de $532 \mathrm{~nm}$ y unos pulsos de menos de $10 \mathrm{~ns}$. Estos láseres son especialmente útiles cuando los angiomas planos forman lesiones tuberosas, en las lesiones vasculares finas o de pequeño calibre y las superficiales $(6,8,9)$.

Los sistemas de láser en modo QS ○ Q-Switched (Alejandrita, rubí, Nd-YAG) entregan a la piel pulsos de energía de alta intensidad, en una fracción muy corta de tiempo, que alcanza de manera selectiva el cromóforo diana, ocasionando en éste un gradiente de temperatura que a su vez origina la dilatación termoelástica del cromóforo y la transformación de la energía lumínica en calor, que se disipa al medio circundante más frío sin dañarlo, y una onda mecánica que finalmente fragmenta la diana (efecto fotoacústico).

El láser más empleado es el de Nd:YAG, que utiliza una onda continua de luz infrarroja a $1.064 \mathrm{~nm}$, con una penetrabilidad en la piel entre 5 y $7 \mathrm{~mm}$. Su mayor longitud de onda le permite una mayor penetrancia que el LCP, llegando hasta estructuras cutáneas situadas a 5-7 $\mathrm{mm}$ de profundidad. Sin embargo, al no presentar una longitud de onda en el rango de la absorción de la oxihemoglobina, su efecto es menos selectivo, produciendo una destrucción tisular circundante. Puede aplicarse de modo intralesional a través de un catéter introducido en el interior de la lesión, visualizándose el proceso mediante control ecográfico. Sobre la mucosa se recomienda utilizar una potencia constante de 30 vatios, una fibra de 600 rm de diámetro y una duración del pulso variable. Al incidir el impacto en la mucosa se observa una retracción inmediata del área tratada y la aparición de unos puntos blanquecinos que son útiles para no solapar los impactos. En las grandes malformaciones venosas de la mucosa la aplicación del láser, previa a la cirugía, permite eliminar el componente superficial de la malformación y crear una banda de fibrosis que facilita una mejor disección de la lesión, disminuyendo el sangrado durante la intervención. De todas formas, aunque la tolerancia es mejor, con ausencia de púrpura, pueden producir mayor incidencia de cicatrices o alteraciones en la pigmentación que el LCP (10).

Las ventajas de la vaporización con el láser de $\mathrm{CO}_{2}$ frente al $\mathrm{Nd}$ :YAG son: a) la profundidad de la destrucción puede ser visualmente controlada, b) la curación de la herida quirúrgica es más rápida. Entre sus desventajas se encuentra el sangrado, la formación de humo y la menor penetración en el tejido.

\section{INDICACIONES DE LOS SISTEMAS LÁSER}

Debemos incluir varios grupos de enfermedades que afectan a los genitales masculinos y sus tratamientos con los diferentes tipos de láseres más empleados: 
- Lesiones inflamatorias: balanitis xerótica obliterans.

- Lesiones producidas por virus: condilomas acuminados.

- Neoplasias: carcinoma epidermoide in situ, carcinoma escamoso invasivo y carcinoma verrucoso (Tabla I) (11).

- Lesiones vasculares adquiridas y congénitas (malforma ciones vasculares cutáneas y los hemangiomas).

- Lesiones pigmentadas: nevus melanocítico adquirido y congénito, nevus epidérmico, mácula melánotica, queratosis seborreicas y tatuajes.

La balanitis xerótica obliterans $(\mathrm{BXO})$ es una variante del liquen escleroso y atrófico, limitada al glande y al prepucio. Es una de las causas más comunes de fimosis secundaria, tanto en adultos como en niños, y de estenosis del meato uretral (Figura 1). El verdadero problema de estas lesiones es la transformación maligna, especialmente el carcinoma espinocelular, en particular en las lesiones de muy larga evolución. Hasta un $30 \%$ de los carcinomas epidermoides de pene se desarrollan sobre una BXO (12). Existen 5 casos publicados en los que la lesión preexistente sea un liquen plano. Dentro de los subtipos histológicos del liquen plano, el hipertrófico es el que más se asocia al carcinoma epidermoide (13).

Los tratamiento clásicos que se han empleado son los corticoides tópicos y la circuncisión, que sólo es efectiva si se limita al prepucio.

El láser de $\mathrm{CO}_{2}$ permite la destrucción del tejido afectado, previniendo la aparición de neoplasias malignas,

\section{TABLA I. LESIONES PREMALIGNAS Y MALIGNAS LOCALIZADAS EN EL PENE 1111.}

\section{Premalignas}

- Balanitis xerótica obliterans

- Condiloma acuminado. Tumor de

Buschke-Löwenstein

- Leucoplasia

- Fibroepitelioma premaligno de Pinkus

- Balanitis pseudoepiteliomtosa

queraátosica y micácea

\section{Carcinoma in situ}

- Enfermedad de Bowen

- Papulosis bowenoide

- Eritroplasia de Queyrat

Carcinoma epidermoide invasivo

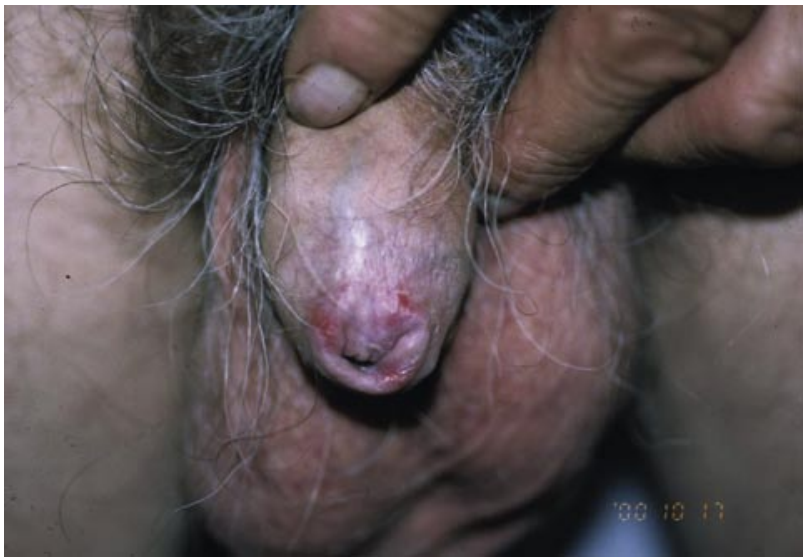

FIGURA 1. Balanitis xerótica obliterans.

con excelentes resultados estéticos y funcionales. El método empleado consiste en vaporizar con el haz desenfocado el área macroscópicamente alterada a una potencia de 8 a $20 \mathrm{~W}$. Los mejores resultados se obtienen en el glande. Si el meato está estenosado, debe completarse con meatomía o bien vaporización circunferencial del meato uretral, ésta última es muy efectiva (14) (Figuras 2, 3 y 4).

Los condilomas acuminados son lesiones producidas por la infección del virus del papiloma humano, en especial los serotipos 6 y 11 . La localización más frecuente es en el pene, escroto y uretra. Su curso clínico es variable, desde la desaparición espontánea hasta la degeneración neoplásica, particularmente con los serotipos 16,18 y 31 (Figuras 5 y 6 ).

Los tratamientos se basan en la destrucción química o física de las lesiones. En los genitales externos se emplea los tratamientos tópicos como la toxina de podofilino $0.5 \%$ y fluoracilo $5 \%$. La inmunoterapia, incluye inmunoreguladores tópicos (imiquimod 5\%) o sistémico (interferón). Dentro de los tratamientos físicos, se emplea crioterapia, electrocauterización y el láser de $\mathrm{CO}_{2}$.

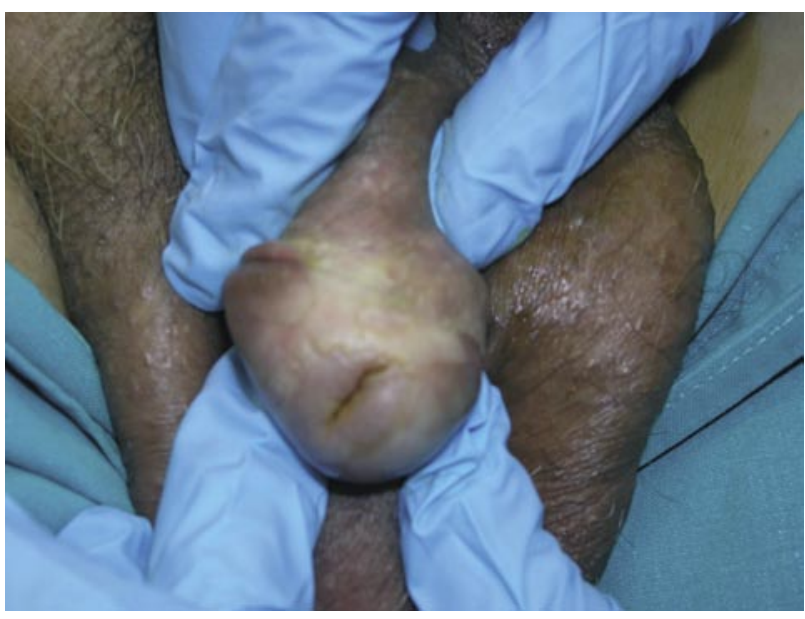

FIGURA 2. Liquen escleroatrófico antes del tratamiento con láser de $\mathrm{CO}_{2}$. 


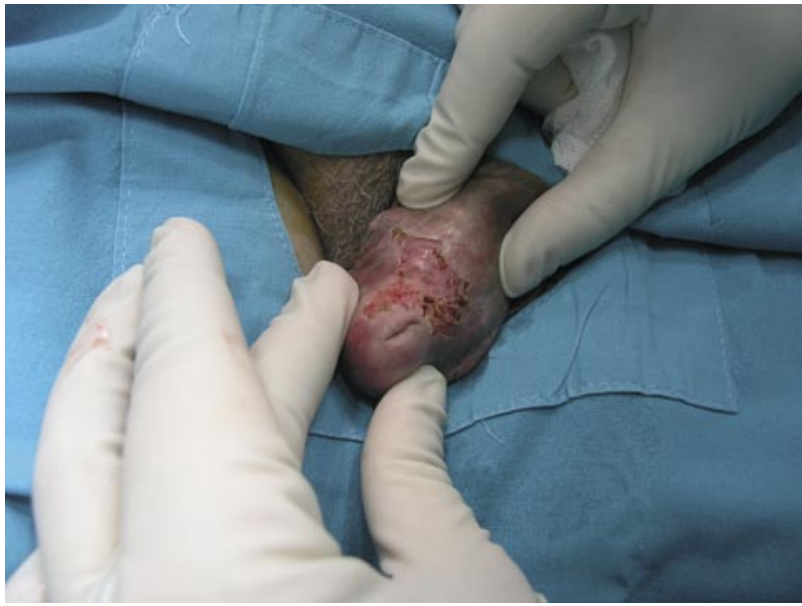

FIGURA 3. Liquen escleroatrófico después del tratamiento con láser de $\mathrm{CO}_{2}$

La vaporización con láser de $\mathrm{CO}_{2}$ se aplica en la lesión y en la piel adyacente a $5 \mathrm{~mm}$. Tiene la ventaja de una baja incidencia de alteración de la uretra. Elimina las lesiones y reduce las tasas de recidiva, pero no es capaz de erradicar el genoma del virus del papiloma humano. Además, hay que tener en cuenta que el humo producido con el láser contiene gran cantidad de partículas virales, con riesgo potencial de transmisión al personal sanitario.

En los condilomas gigantes o tumor de BuschkeLöwenstein, no es útil el lasér de $\mathrm{CO}_{2}$, sino el láser de $\mathrm{Nd}$ : YAG, dado que tiene más poder de penetración en el tejido (10) (Figura 7).

Aproximadamente el $20 \%$ de los condilomas se localizan en la uretra, preferentemente en el meato externo de la uretra $(15,16)$ (Figura 8). Sin embargo, también se localizan en la uretra proximal siendo necesario el diagnóstico endoscópico. El difícil acceso de los condilomas localizados en la uretra y que la mayoría de los fármacos empleados en los genitales externos no están permitidos para el tratamiento específico de los condilomas localizados en

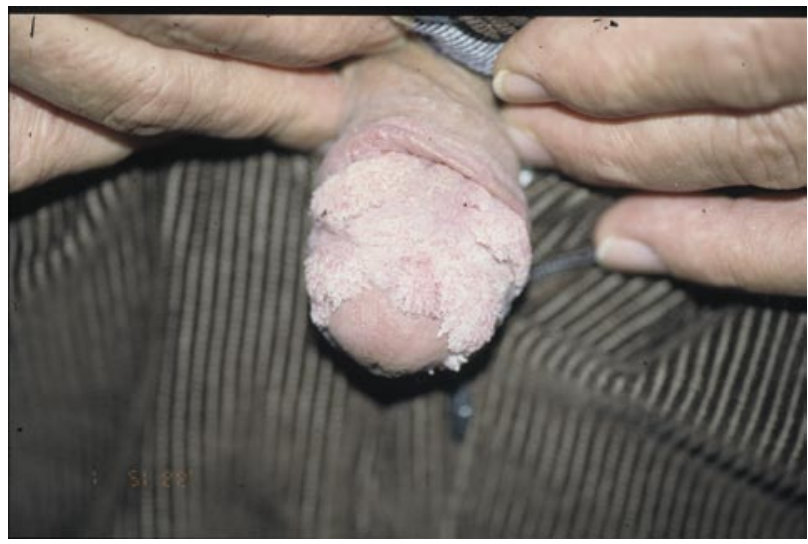

FIGURA 5. Condilomas acuminados.

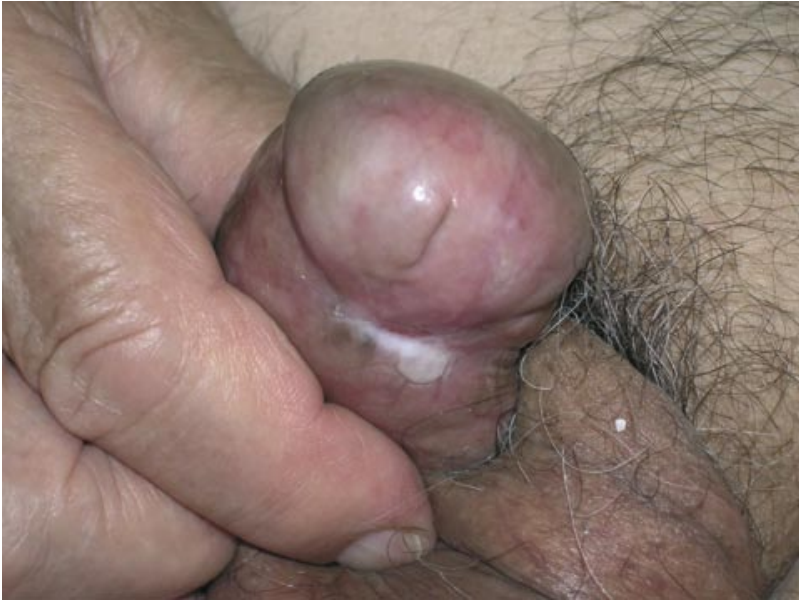

FIGURA 4. Liquen escleroatrófico, un mes después de la primera sesión de láser de $\mathrm{CO}_{2}$.

la uretra, excepto en el meato externo de la uretra, debido a los efectos secundarios, hacen que el tratamiento sea difícil (17). Además son más frecuentes las recidivas de los condilomas localizados en la uretra que en los genitales externos, por lo que sigue siendo un problema médico sin resolver y un desafío terapéutico. Hay que tener en cuenta el riesgo de diseminación del virus HPV por la instrumentación.

Debido a razones técnicas el láser $\mathrm{CO}_{2}$ tampoco es apropiado emplearlo en los segmentos proximales de la uretra. El láser ND-YAG teóricamente tiene los requisitos ideales pare ser efectivos para el tratamiento de los condilomas uretrales debido a uso endoscópico así como la posibilidad de control de la profundidad de penetración. Por tanto, el tratamiento recomendado en los condilomas intrauretrales es el láser Nd-YG debido a la posibilidad de empleo tópico y endoscópico (18). Sin embargo, el láser holmium:YAG puede ser una alternativa terapéutica al láser Nd-YAG. La profundidad de penetración es menor que el láser Nd-YAG, pero puede ser suficiente para el tratamiento con los condilomas intrauretrales y causaría menos cicatriz (16).

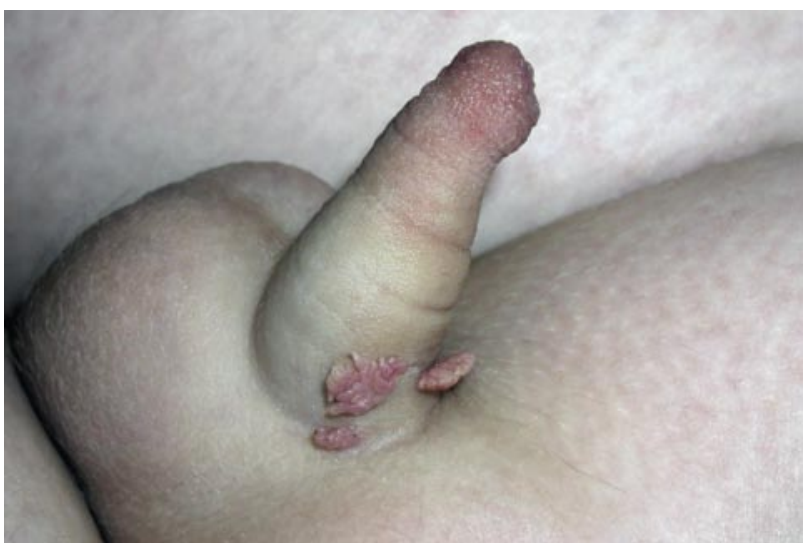

FIGURA 6. Condilomas acuminados en un niño. 
En algunos estudios recomiendan el tratamiento con láser $\mathrm{Nd}-\mathrm{YAG}$ endoscópicamente bajo control con fluorescencia mediante 5-ALA que la técnica endoscópica convencional de láser en los condilomas uretrales, dado que han observado una disminución del porcentaje de recurrencias en el área tratada (16).

Algunos autores recomiendan la terapia adyuvante, empleando 5-fluoracilo, o interferón alfa 2B, con el intento de prevenir el desarrollo de las recurrencias (19).

Los efectos secundarios del láser son las malformaciones de la uretra, dolor, erosión, úlceras, hiperpigmentación e hipopigmentación.

Las neoplasia más frecuentes localizadas en los genitales externos son las formas in situ o el carcinoma de células escamosas invasivo (20) (Tabla I).

La papulosis bowenoide es una enfermedad en controversia (Figura 9). Se ha encontrado el virus del papiloma humano tipo 16, 34 y 42. Está considerada una displasia que puede o no progresar a un carcinoma in situ o invasivo, aunque es poco frecuente la progresión a la malignidad. Tiene buen pronóstico. Se ha empleado el láser de $\mathrm{CO}_{2}$ y de $\mathrm{Nd}$ :YAG o el láser de argón con buenos resultados (20).

Tis o tumor in situ son la Eritroplasia de Queyrat y la enfermedad de Bowen (Figura 10). En un 5\% de los pacientes se produce una enfermedad metastásica mortal. No hay una guía terapéutica uniforme. Se ha empleado excisión del tumor con penectomia parcial o total, circuncisión y cirugía micrográfica de Mohs, así como radioterapia, fluoracilo $5 \%$, electrocauterización, crioterapia y terapia fotodinámica.

Otras modalidades terapéuticas son el láser de $\mathrm{CO}_{2}$ y de $\mathrm{Nd}$ :YAG, pero el riesgo de recidiva es alto.

El láser de $\mathrm{CO}_{2}$ se emplea con una potencia de 3-5 vatios con el haz desenfocado, pudiendo ser utilizado

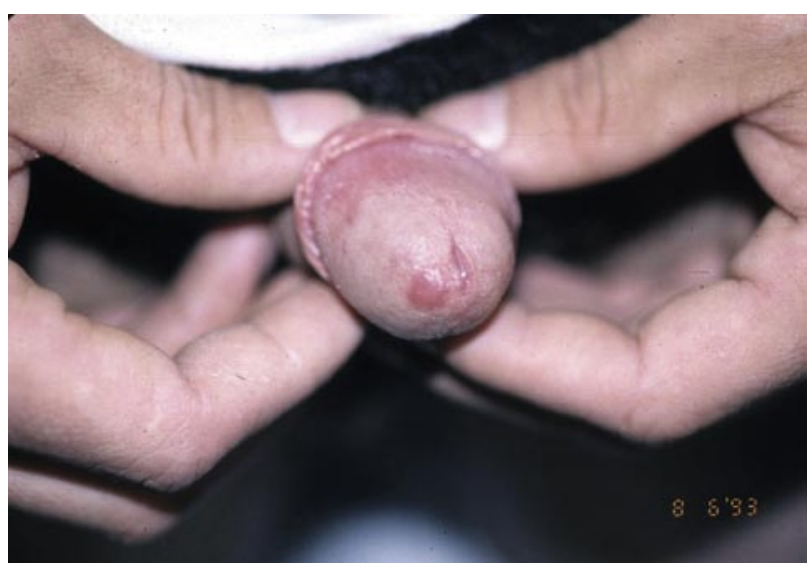

FIGURA 7. Condilomas periuretral. tanto en modo continuo como superpulsado, si bien este último reduce la necrosis y el edema, acortando la curación. Se recomienda vaporizar 2-3 mm de margen de tejido clínicamente sano. La reepitelización completa es a las 2-6 semanas. Aunque el resultado es muy satisfactorio, con mínimas lesiones residuales, a veces puede quedar una cicatriz. Requiere seguimiento clínico y realización de una biopsia ante la mínima sospecha de persistencia de tumor. Si presenta ulceración sugiere que la lesión está invadiendo, y convirtiéndose en un carcinoma escamosos invasivo con riesgo de afectación de la submucosa, o de metástasis ganglionares o a distancia (20).

El carcinoma epidermoide de pene es una rara patología en nuestro medio, que no supera la frecuencia del $1 \%$ de todos los cánceres de piel en varones. Las dos variedades anatomo-clínicas más frecuentes son el carcinoma escamoso de pene (CEP), con una frecuencia del $90 \%$ y el carcinoma verrucoso (CV) en el 6-10\% de los casos (20) (Figuras 11, 12 y 13).

Las lesiones consideradas precursoras del CEP son: la presencia de fimosis; la balanitis xerótica obliterans; la leucoplasia y el cuerno cutáneo. El pronóstico empeora en aquellos pacientes con cáncer invasivo, mala diferenciación celular, morfología úlcero-endofítica, y sobre todo, viene determinado por la afectación ganglionar (20).

En la actualidad el tratamiento de elección sigue siendo la extirpación quirúrgica, la penectomía parcial con un margen de seguridad de al menos $2 \mathrm{~cm}$. También se recomienda la excisión del tumor, la circuncisión o la extirpación quirúrgica mediante cirugía micrográfica de Mohs (20).

No obstante, debe tenerse en cuenta como alternativas terapéuticas el láser de $\mathrm{CO}_{2}$, de $\mathrm{Nd}$ :YAG y con menor frecuencia el láser de argón, empleándose de forma aislada o combinada (21). La técnica elegida será la vaporización o la escisión en bloque, dependiendo del tamaño de la masa tumoral. Si el tumor es de pequeño tamaño, se optará por la vaporización con una potencia de 5-10W, además de realizar varios pases con la finalidad de au-

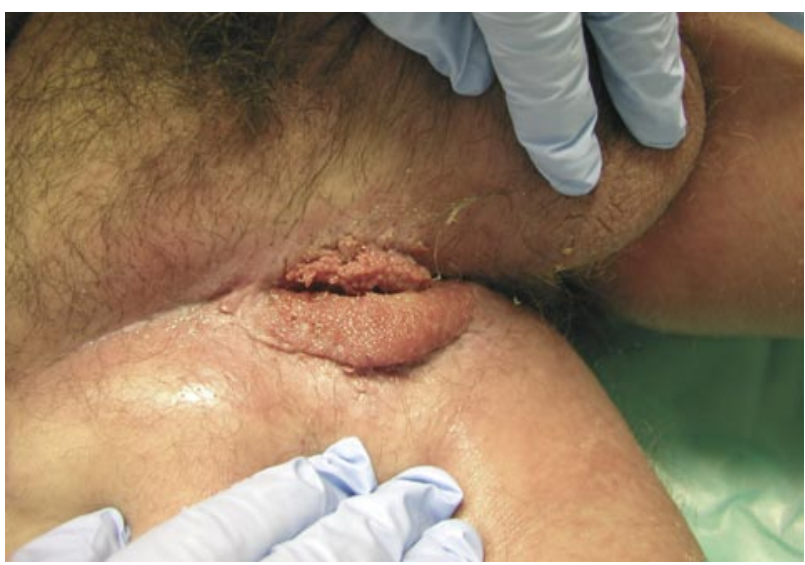

FIGURA 8.Condiloma gigante o tumor de Buschke-Löwenstein 


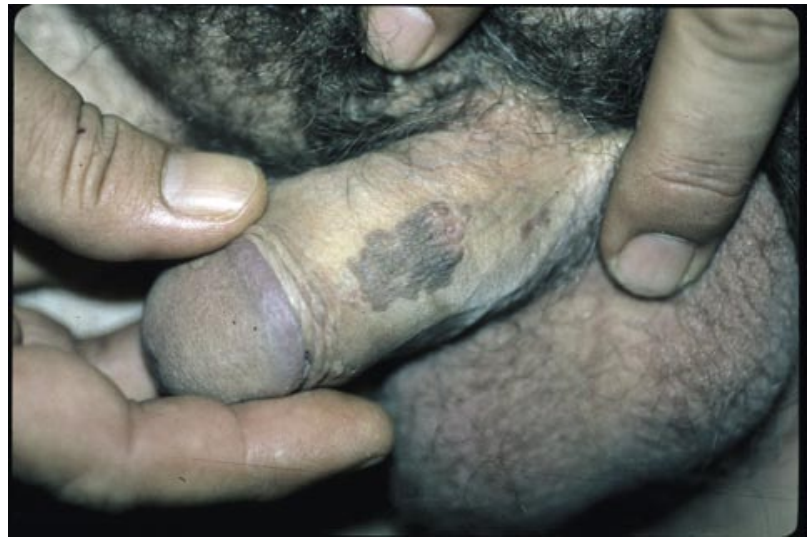

FIGURA 9. Papulosis bowenoide.

mentar la penetración en el tejido y destruir la totalidad del tejido afectado. En ocasiones se ha empleado el láser para escindir el tumor en bloque y examinarlo microscópicamente de forma intraoperatoria para asegurarse que los márgenes quedan libres, pudiendo continuar la escisión de tejido hasta que todo el tumor haya sido eliminado. Este procedimiento es similar a la cirugía de Mohs, aunque con la ventaja de que el láser proporciona en esta zona un menor sangrado (22).

El tratamiento con láser tiene el inconveniente de un alto riesgo de recurrencia local, siendo de más del $50 \%$ con el láser de $\mathrm{CO}_{2}$ y con $\mathrm{Nd}$ :YAG del 10\%, porque penetra de forma más profunda y coagula los vasos más grandes. El porcentaje de recurrencias después del tratamiento con láser Nd-YAG es comparable a la amputación parcial $(1,23)$.

En carcinoma verrucoso es una variante del carcinoma de pene, con buen pronóstico, siendo muy raro que metastatize, pero su comportamiento a nivel local es agresivo, pudiendo penetrar hasta los cuerpos cavernosos

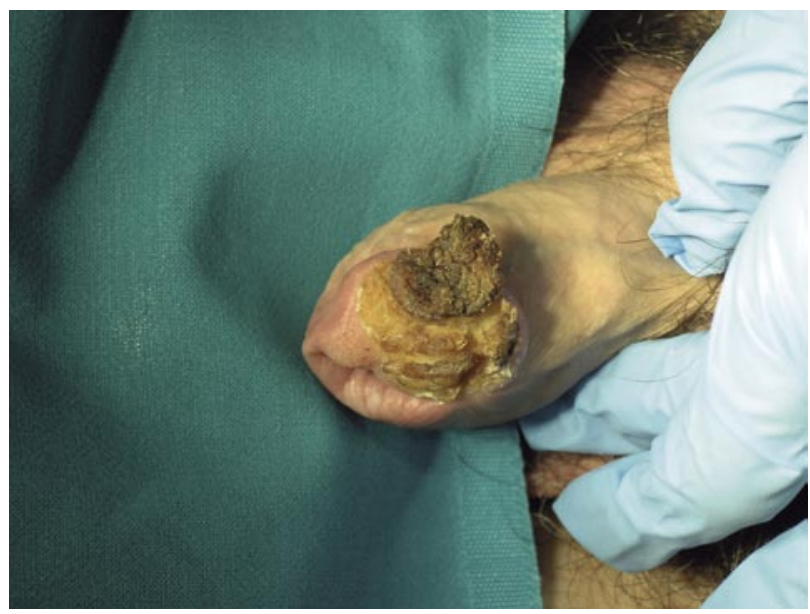

FIGUR 11. Carcinoma escamoso de pene.

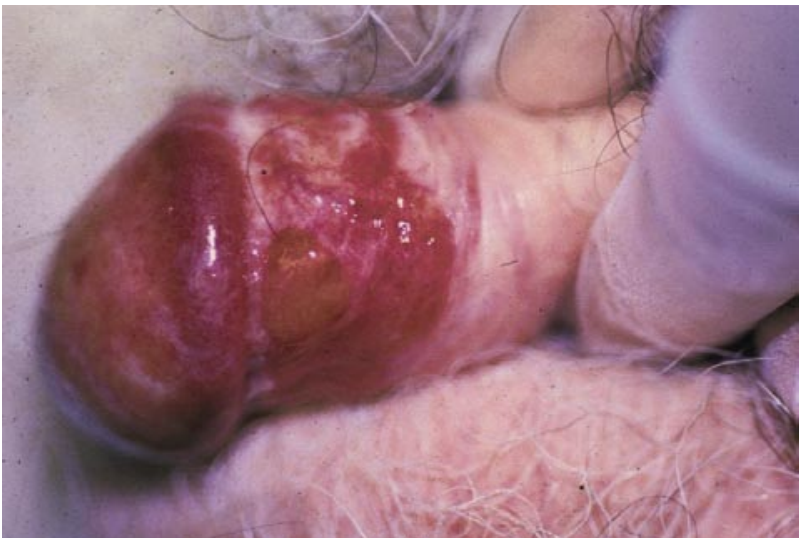

FIGURA 10. Eritroplasia de Queyrat.

y la uretra. Con frecuencia su aspecto macroscópico es indiferenciable del carcinoma epidermoide con crecimiento exofítico, precisando de una biopsia excisional profunda para un diagnóstico definitivo. En muy pocos caso coexiste un CV de pene con focos de CEP invasivo, son los denominados "híbridos". El tratamiento recomendado es la cirugía conservadora (penectomía parcial) (1).

Se ha empleado el láser como una alternativa terapéutica, pero presenta un riesgo de recurrencia local. El laser más adecuado es el $\mathrm{Nd}$-YAG se emplea en modo continuo a 23 a 50 vatios, con un margen de seguridad recomendado de 5-8 $\mathrm{mm}$, con un mínimo de 2-3 mm (consiguiendo profundidad de al menos 3 a $4 \mathrm{~mm}$ ). Este láser tiene mayor capacidad de penetración tisular, empleándo-

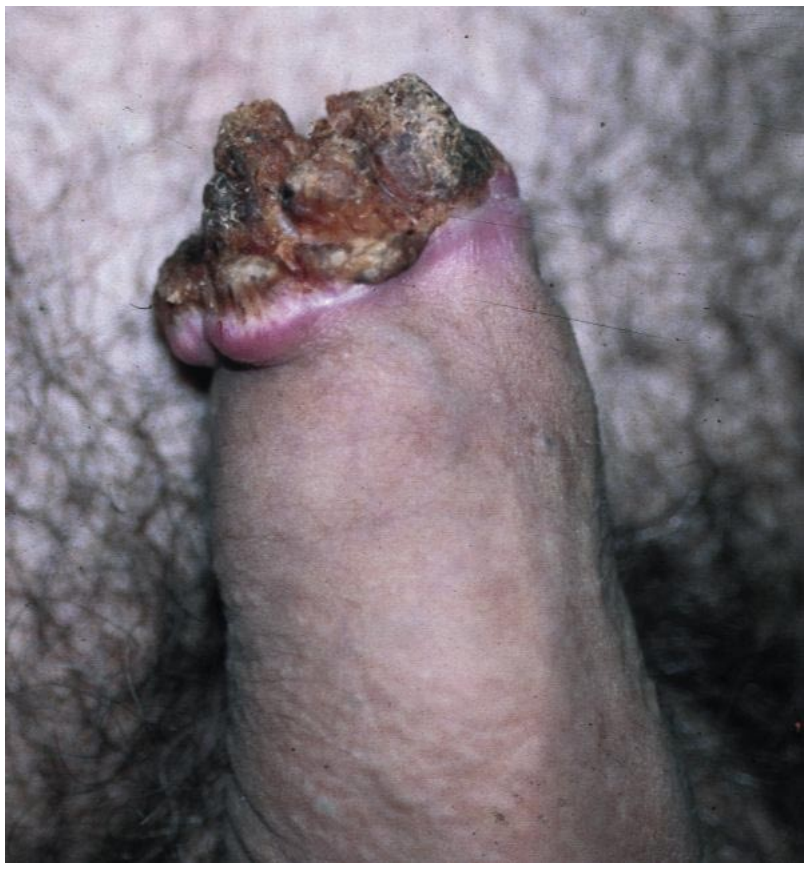

FIGURA 12. Carcinoma escamoso de pene. 
se en los casos de tumor de gran tamaño o que penetra profundamente. Los factores limitantes son el tamaño y el grado de diferenciación del tumor.

Se puede emplear el láser de $\mathrm{CO}_{2}$, en modo continuo a una potencia mayor de 15 vatios (24). También se ha utilizado combinado, primero se emplea el láser de $\mathrm{CO}_{2}$ con una potencia de 20 vatios con excisión de toda la lesión macroscópicamente con un margen de 3 a $5 \mathrm{~mm}$. Tras la excisión del tumor, se aplica el laser de Nd-YAG, con una potencia de 40 a 60 vatios, y con una profundidad de penetración de 3 a 5 mm, sobre el lecho tumoral. La combinación de láser de $\mathrm{CO}_{2}$ y $\mathrm{Nd}$ :YAG, está considerando como un excelente tratamiento conservador en el carcinoma de pene en los estadios in situ a T2NOMO, grado 1 y 2 (20).

Si hay afectación de la uretra distal o está próxima deberá tener un sondaje uretral durante una semana.

Aunque el tratamiento con láser supone una magnífica alternativa en el tratamiento del carcinoma de pene, deben igualmente considerarse sus inconvenientes, como son: 1) el tejido tumoral eliminado no puede ser examinado al microscópico (excepto con la técnica escisional), con lo cual, no existe confirmación histológica de márgenes quirúrgicos adecuados, 2) la reepitelización completa puede ser larga, sobre todo, si se emplea el láser Nd:YAG, haciendo difícil la detección del tumor residual. Si la curación se prolonga más de dos meses, debe realizarse biopsia, por sospecha de persistencia o recidiva tumoral, 3) el daño térmico puede producir una respuesta inflamatoria en los ganglios inguinales durante varios meses, que puede inducir a error con las metástasis regionales.

El láser de $\mathrm{CO}_{2}$ puede utilizarse a modo de bisturí y es capaz de coagular los vasos entre 0.5 y $1.5 \mathrm{~mm}$ a la vez que corta, y sin causar efecto térmico en los tejidos sanos de alrededor, en los casos de grandes tumores muy vascularizados, como los sarcomas cutáneos o los tumores de la mucosa genital o la enfermedad de Paget extramamaria con afectación peno-escrotal $(1,25,26$.) (Figura 14).

Las lesiones vasculares congénitas son fundamentalmente las malformaciones vasculares cutáneas y los hemangiomas. Las malformaciones vasculares pueden ser capilares (nevus flammeus, mancha en vino de oporto, malformaciones vasculares capilares o angioma plano), venosas, linfáticas (linfangioma, higroma) y arteriales, o combinadas. Los hemangiomas son superficiales (hemangiomas capilares o en fresa), profundos (hemangioma cavernosos) o mixtos, aunque hoy en día suelen clasificarse como focales o segmentarios.

Las malformaciones vasculares localizadas en el área genital, son extremadamente raras, suponiendo alrededor del $1 \%$ de todas las malformaciones, y son extremadamente raras las de localización peneana. Los hemangiomas capilares y cavernosos son las más frecuentes (27). Con el láser de luz pulsada intensa, de colorante pulsado, el de Nd-YAG y de argón se consiguen aclaramientos del $80-90 \%$ en los angioma planos y los hemangiomas $(1,28)$

En general, las lesiones vasculares superficiales, con vasos de menor calibre y flujo (malformaciones capilares, hemangiomas en edades tempranas) responderán mejor a los láseres con longitudes de onda entre 500 y 600 $\mathrm{nm}$, fluencias bajas y pulsos cortos. Las lesiones situadas a mayor profundidad, con vasos de mayor calibre y mayor calibre y flujo (malformaciones venosas, componente profundo de los hemangiomas) responderán a longitudes de onda entre 800 y 1100 nm, fluencias altas y pulsos largos y superlargos.

El principal factor pronóstico en la respuesta al tratamiento con el láser en las malformaciones vasculares son la profundidad media y el diámetro de los vasos dilatados. Así, los angiomas planos con vasos más superficiales presentan una mejor respuesta. Éstos pueden tratarse con diversos láseres. Hoy día existe un amplio consenso en la utilización del láser de colorante pulsado (LCP) como tratamiento de primera línea en estos pacientes, particularmente en niños. Sin embargo, la erradicación completa de la lesión se produce sólo en una pequeña minoría de pacientes. La gran mayoría de los pacientes tratados con el LCP con pulsos entre 0.4 y 2 ms, presentan un aclaramiento parcial de su lesión, en menor o mayor grado (9). En el angioma con componente tuberoso el tratamiento

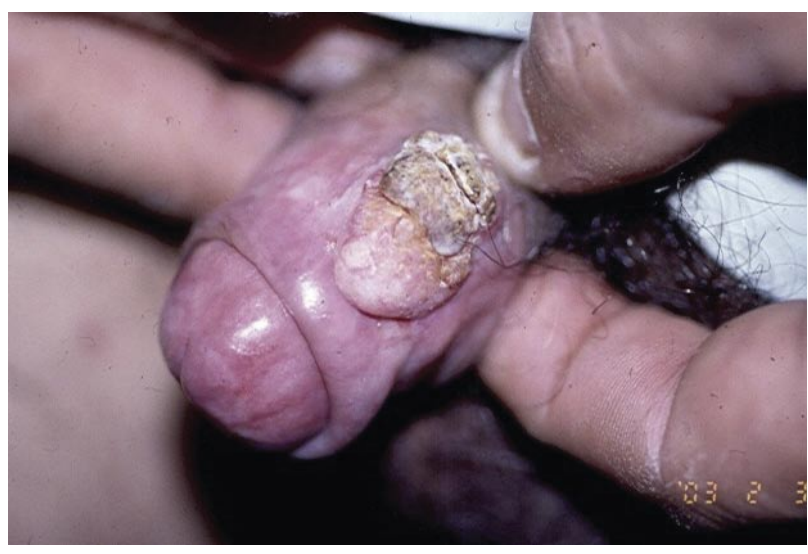

FIGUR 13. Carcinoma verrucoso de pene.

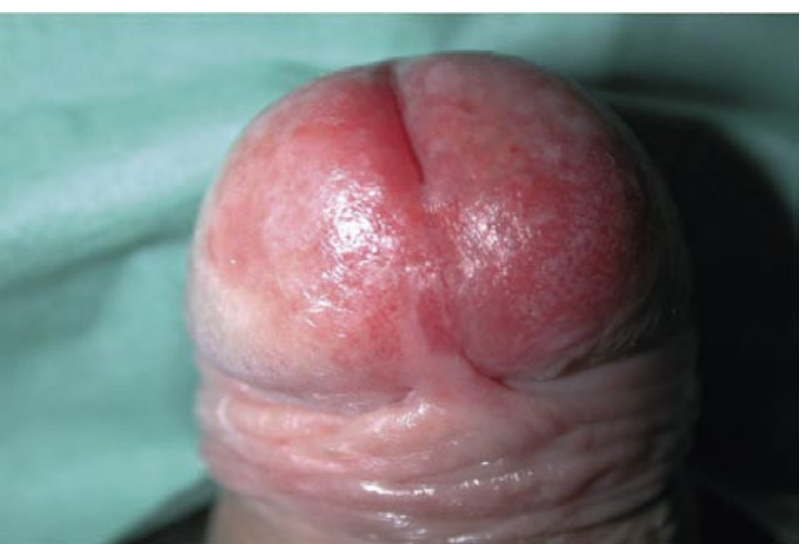

FIGURA 14. Enfermedad de Paget de localización en pene. 
se reserva únicamente si existe sangrado, infecciones o razones estéticas.

Los hemangiomas capilares 0 en fresa es el tumor más frecuente de la infancia. Existen dos "ventanas" o períodos en la evolución del hemangioma en los cuales puede ser útil el tratamiento con láser. La primera, en el inicio de la fase proliferativa, aunque se ha descrito ocasionalmente complicaciones con ulceraciones (especialmente en hemangiomas segmentarios), y también para el tratamiento del componente vascular residual una vez ha involucionado el hemangioma. A pesar de las controversias acerca del momento más apropiado para iniciar el tratamiento con láser, en general se admite que debe ser lo más precoz posible (29). Respecto al intervalo entre sesiones el estándar clásico es con un mínimo de 6 semanas de diferencia.

El LCP y El KTP son resolutivos para tratar el componente superficial de esta lesión. Su tratamiento está justificado en los casos de sangrado y ulceración (30,31). El componente profundo puede responder a los láseres de una mayor longitud de onda y pulsos largos como el $\mathrm{Nd}$ : YAG.

El hemangioma cavernoso es una patología benigna, pero dada su tendencia a invadir en profundidad, se recomienda tratarlos. Pueden presentar sangrado, infección y alteración cosmética y en ocasiones, molestias en la erección. Los tratamientos empleados son la radioterapia, crioablación, electrofulguración o la extirpación quirúrgica, pero se ha asociado con importantes pérdidas de tejido y una prolongada hospitalización. Además, si la lesión vascular está localizada cerca del meato o son de gran tamaño, la cirugía puede producir estenosis del meato o tener malos resultados cosméticos y funcionales. El tratamiento con láser puede coagular los tejidos y extirpar la lesión sin pérdidas hemáticas significativas, por lo que algunos autores consideran el tratamiento de elección el láser, y en particular el láser de Nd:YAG (32).

El láser Nd-YAG se ha empleado con buenos resultados funcionales y cosméticos. Su mayor longitud de

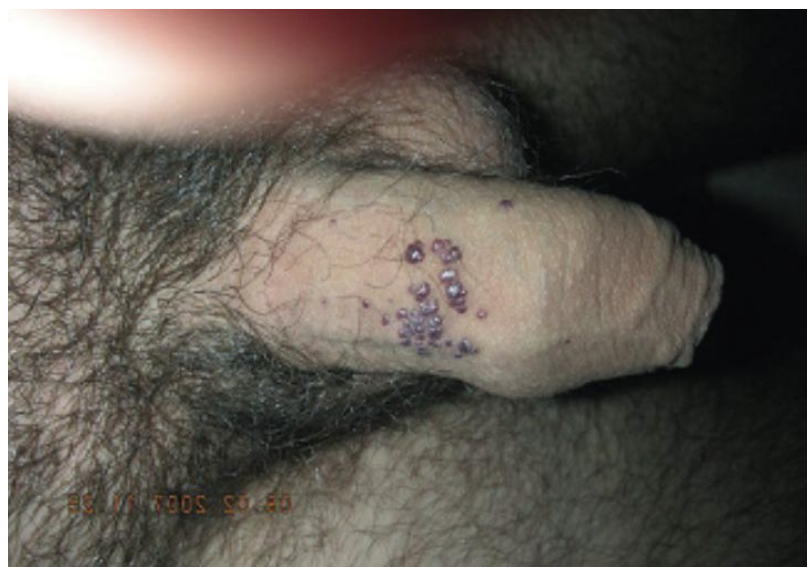

FIGUR 15. Angioqueratomas de Fordyce antes del tratamiento con $L C P$. onda, de $1.064 \mathrm{~nm}$, le permite una mayor penetrancia, llegando hasta estructuras cutáneas situadas a $5-7 \mathrm{~mm}$ de profundidad. Sin embargo, al no presentar una longitud de onda en el rango de la absorción de la oxihemoglobina, su efecto es menos selectivo, produciendo una destrucción tisular circundante. Se aplica en modo desenfocado, con una potencia a 10-15 vatios y con una duración del pulso de 2-3 segundos de forma circunferencial a lo largo de la lesión para eliminar el suministro vascular y descomprimir el hemangioma. El remanente persistente de la lesión es coagulada hasta el colapso completo y observar la piel o mucosa blanca o la descoloración. No se ha observado estenosis en el meato tras el tratamiento. Es conveniente el sondaje uretral antes del tratamiento y durante una semana cuando la lesión está próxima al meato (33). El tratamiento de los hemangiomas cavernosos y mixtos ha mejorado mucho desde la aparición del láser de Nd-YAG de aplicación superficial, y es éste, junto a la embolización selectiva arterial, cuando es posible, el mejor tratamiento que hay en la actualidad (1).

Las malformaciones venosas son máculas, pápulas o nódulos azuladas o violáceas. Suelen estar presentes al nacimiento aunque a veces no son tan patentes hasta la edad adulta. El enfoque terapéutico dependerá de caso particular, empleando la cirugía, escleroterapia o el láser. El láser de longitudes de onda entre 800 y 1100 nanómetros y pulsos largos (diodo, Nd:YAG) son útiles en algunos casos. En las pequeñas lesiones superficiales, también se emplea la LIP y el LCP, pero su respuesta es más lenta (9). Hasta un tercio de los pacientes no mejoran a pesar de múltiples sesiones, en parte por la limitada penetrabilidad del láser en el tejido ( 1 a $1.5 \mathrm{~mm}$ ), que impide tratar vasos localizados a mayor profundidad, y en parte también porque pueden existir otros elementos no vasculares de tipo hamartomatoso que no son diana de esta tecnología (34). En estos casos los láseres de $\mathrm{CO}_{2}$ o de $\mathrm{Nd}$ :YAG también son eficaces (8). En casos y zonas resistentes la administración de un doble pase con el láser de colorante pulsado mejora la respuesta. También se ha demostrado cómo el solapamiento de los impulsos puede favorecer la penetrabilidad, sin asociar efectos secundarios sobre la epidermis (35).

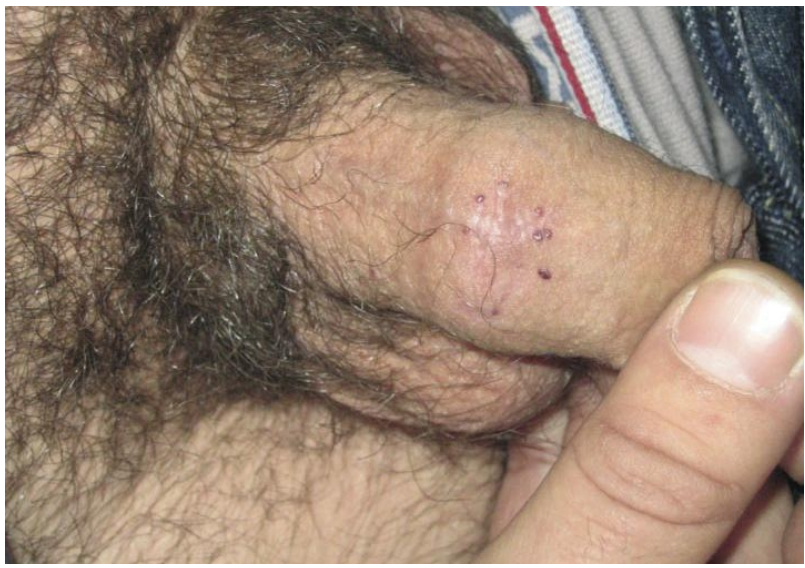

FIGURA 16. Angioqueratomas de Fordyce después de una sesión con LCP. 
Las malformaciones arteriovenosas son tratadas con embolización o escleroterapia y su posterior resección quirúrgica. Si son lesiones no muy profundas y de un flujo no muy elevado puede intentarse el tratamiento mediante el láser de Nd:YAG continuo o de pulsos largos.

Los angioqueratomas de Fordyce son lesiones vasculares adquiridas, asintomáticas, caracterizadas por pápulas rojo-azul de superficie rugosa, localizadas frecuentemente en escroto, y en el pene. Aunque son lesiones benignas, las lesiones pueden ser profundas, con sangrado. Los tratamientos empleados incluyen la electrocoagulación, excisión, crioterapia y el láser.

El LCP es efectivo y seguro con mínimos efectos secundarios. Se emplea con spot de $5 \mathrm{~mm}$ y una fluenza de 5.5 a $8 \mathrm{~J} / \mathrm{cm}^{2}$ y duración del pulso de $0.45 \mathrm{~ms}$, tratadas dos veces, consecutivamente, en la misma sesión, con intervalos de 2 meses (Figuras 15 y 16). El LCP puede ser una alternativa al láser de argón, KTP y Nd-YAG, con mayor seguridad (36).

Las malformaciones linfáticas superficiales de las mucosas (linfangioma), generalmente son lesiones difusas que alcanzan planos profundos, incluyendo el músculo subyacente (Figura 17). Se han tratado con exéresis, electrocauterización y criocirugía. La cicatriz consecuente de cualquier terapia puede desarrollar linfangiomas, por lo que presenta una alta tasa de recurrencia.

La ablación con el láser de $\mathrm{CO}_{2}$ está indicada especialmente en esta patología. Se emplea en modo continuo, desenfocado y a una potencia de 20 vatios. No es un tratamiento curativo, pero permite controlar la enfermedad y mejorar de forma evidente la calidad de vida de los pacientes. A pesar de ello, la recurrencia es la norma y son necesarios tratamientos periódicos. Como la infección asociada puede estimular el crecimiento de una malformación linfática, se aconseja realizar el procedimiento bajo una cobertura antibiótica tópica y sistémica y antiinflamatoria con corticoides orales (37).

En las lesiones pigmentadas, los láseres no selectivos utilizados para la resurfactación, como el $\mathrm{CO}_{2}(10600$

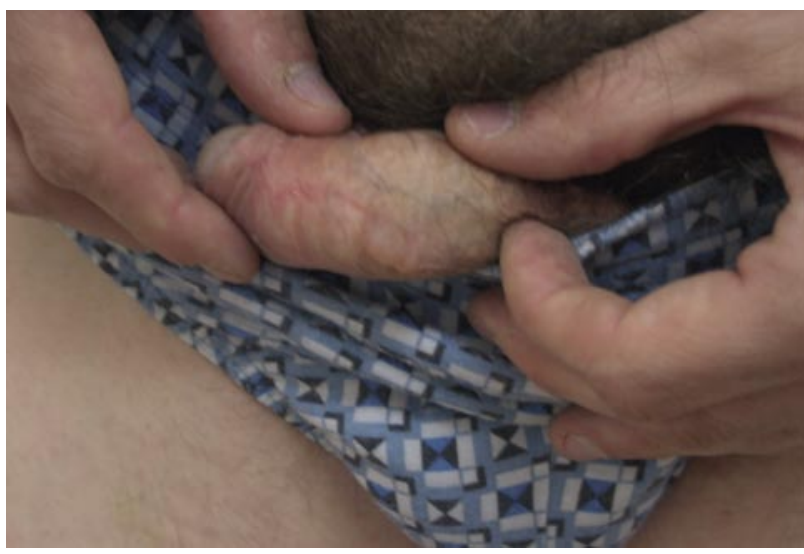

FIGUR 17. Linfangioma en pene. $\mathrm{nm})$ y Er:YAG (2940 nm), pueden eliminar el pigmento superficial epidérmico (38). Eliminan las capas de tejido con alta concentración de pigmento, permitiendo posteriormente la actuación de láseres más selectivos.

Las máculas melanóticas o lentigos y la queratosis seborreicas (Figuras 18 y 19) poco elevadas responden completamente y rápidamente a los láseres de conmutación Q (Q-switched, QS) (39-41). Se emplea un dispositivo electroóptico o QS para producir pulsos de duración entre 4-100 ns y potencia elevada $\left(106-9 \mathrm{~W} / \mathrm{cm}^{2}\right)$. Es infrecuente la aparición de alteraciones cicatriciales, texturales y de la pigmentación.

En los nevus epidérmicos, el láser puede ser una opción cuando no puede emplearse otros métodos quirúrgicos o éstos han fracasado. Tradicionalmente se han empleado láseres continuos como el de argón para las partes planas y aterciopeladas, y el $\mathrm{CO}_{2}$ para la zona hiperqueratósica (42). En la actualidad, los láseres de resurfactación $\left(\mathrm{CO}_{2}\right.$ pulsado y Er:YAG) pueden ofrecer una alternativa terapéutica (43). No obstante, estas lesiones no siempre ofrecen buenos resultados con el láser de $\mathrm{CO}_{2}$, sobre todo por la variable profundidad de éstas.

Los nevus congénitos y adquiridos se han tratado con láseres de argón y QS (rubi, Alejandrita y $\mathrm{Nd}$ :YAG) $(44,45)$. En los estudios histológicos muestran que, aunque obtengamos la eliminación clínica de la lesión, permanecen nidos de células en partes profundas del área tratada, lo que puede explicar la eficacia parcial en algunos casos y la recurrencia incluso tras múltiples sesiones. Esta respuesta incompleta se ha atribuido al hecho de que los pulsos cortos no son suficientes para la destrucción térmica de los nidos de células localizados en la dermis papilar. No obstante este tratamiento es un tema controvertido, sobre todo porque se desconocen los efectos de la irradiación láser sobre las células névicas. En la actualidad, se recomienda la terapia láser de los nevus debe considerarse todavía experimental (9)

Nuestro criterio es no extirpar ningún nevus melanocítico adquirido ni congénito mediante láser de $\mathrm{CO}_{2} \mathrm{O}$ aclararlo mediante luz pulsada intensa, pues es indispen-

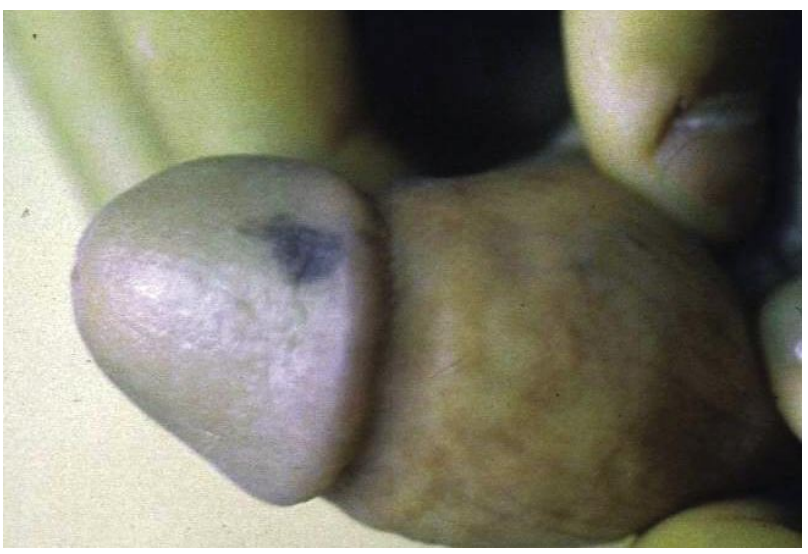

FIGURA 18. Mácula melanótica en glande. 


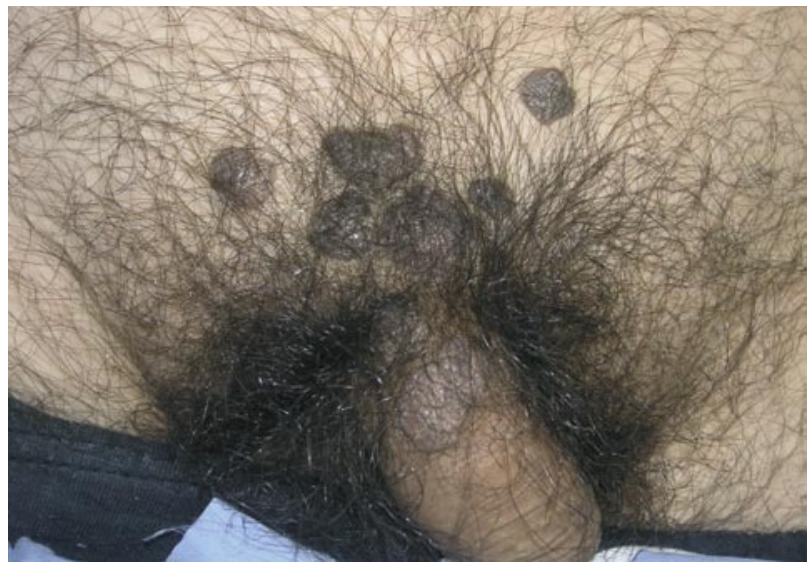

FIGUR 19. Queratosis seborreicas.

sable un diagnóstico anatomopatológico y de control de bordes y no enmascarar su posible evolución a un melanoma. Nunca deben de ser tratadas lesiones de las que no se tiene un diagnóstico claro, sin biopsia previa.

Otras lesiones benignas genitales que pueden ser tratadas con el láser son los quistes epidérmicos o seboquistomatosis (Figura 20). Ésta patología es benigna, pero puede crear importante afectación psicológica. Se pueden tratar mediante la exéresis pero el láser tiene ventajas claras, ya que permite obtener mejores resultados, con menor incidencia de complicaciones y una mejor cosmética $(1,46)$.

\section{CONCLUSIÓN}

En la actualidad el tratamiento con el sistema láser ocupa un lugar importante en la patología genital. Su facilidad de manejo (con posibilidad de empleo endoscópico), eficacia, reducida morbilidad y los excelentes resultados estéticos y funcionales hacen que deba ser considerados una alternativa terapéutica.

Los más empleados son el láser de $\mathrm{CO}_{2}$ y el $\mathrm{Nd}$ : YAG. Se han empleado en el liquen escleroatrófico, la papulosis bowenoide, los carcinomas epidermoides tanto en su variante in situ (Eritroplasia de Queyrat o enfermedad de Bowen), así como el carcinoma invasivo, con buenas respuestas terapéuticas a largo plazo.

También se han utilizado en otras patologías benignas localizadas en el área genital como son las máculas melanóticas o léntigos, queratosis seborreicas, quistes epidérmicos angioqueratomas, linfangioma, verrugas vulgares, condilomas acuminados y nevus epidérmicos. En las lesiones vasculares congénitas y adquiridas el sistema láser más empleado son el LCP y el Nd:YAG, dependiendo de la profundidad de las lesiones. Los láseres selectivos de comutación Q-switched son utilizados para las lesiones pigmentadas (1).

En los pacientes con trastornos de la coagulación o en tratamiento con anticoagulantes se ha aprovechado la capacidad del sellado de los pequeños vasos que produce

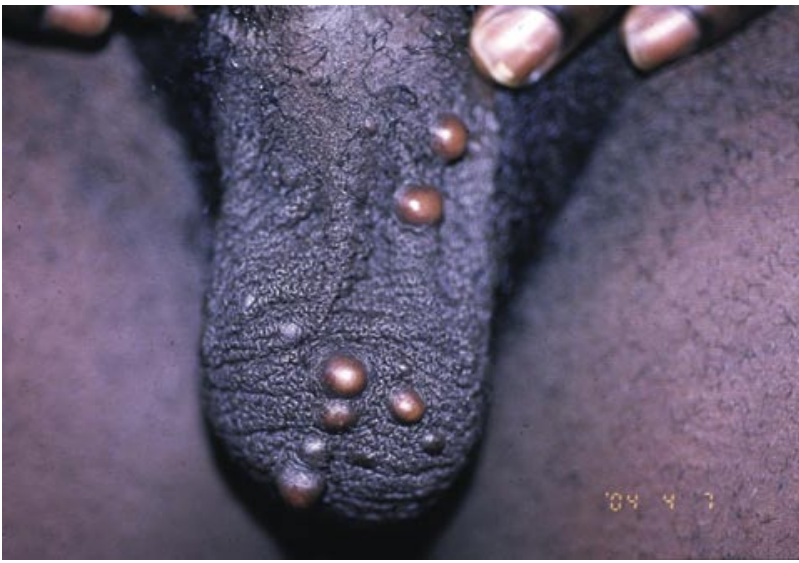

FIGURA 20. Quistes epidérmicos en escroto.

el láser para diversas intervenciones en el área genital. Además, no interfiere con el marcapasos, ni hay riesgo con los fármacos anticoagulantes o hipotensores, por lo que es ideal para el tratamiento de enfermos cardiacos y en ancianos.

Sin embargo, hay enfermedades que no deben orientar al tratamiento con el láser, puesto que prima el diagnóstico anatomopatológico de la entidad y de la extirpación completa o el prevenir la evolución a un cáncer. También hay patologías cuyo tratamiento va a dar un resultado más adecuado mediante técnica quirúrgica, y entre éstas, todas las lesiones más profundas que la dermis reticular.

En conclusión, los diversos tipos de láser de los que disponemos en la actualidad suponen una excelente modalidad terapéutica en el tratamiento de diversas patologías benignas, premalignas y malignas que se localizan en el aparato genital masculino.

\section{BIBLIOGRAFÍA y LECTURAS RECOMENDADAS ( lectura de interés $\mathrm{y}^{* *}$ lectura fundamental)}

**1. PINILLA-LOZANO, M.C.; DUATO-JANÉ, F.: “Aplicaciones del láser en dermatología”. Piel, 5: 91, 2005.

**2. FERNÁNDEZ, J.; ARMARIO, J.C.: "Utilidad de la laserabrasión en dermatología". Piel, 15: 240, 2000.

**3. TRELLES, M.A.; ALLONES, I.; LUNA, R.: "Onepass resurfacing with a combined-mode Er: YAG/CO2 laser system: A study in 103 patients". Br. J. Dermatol., 146: 473, 2002.

4. REDONDO, P.: "Malformaciones vasculares II. Diagnóstico, histopatología y tratamiento". Actas Dermasifiliogr., 98: 219, 2007.

5. ASHINOFF, R.; GERONEMUS, R.G.: "Flashlamppumped dye laser for port wine stains in infancy: Earlier versus later treatment". J. Am. Acad. Dermatol., 24: 467, 1991.

6. LOPEZ, J.L.: "Laserterapia y luz pulsada en las malformaciones vasculares congénitas". Piel, 15: 153, 2000.

*7. GROOT, D.; RAO, J.; JOHNSTON, P. y cols.: "Algorithm for using a long-pulsed Nd: YAG laser in the treatment of deep cutaneous vascular lesions". Dermatol. Surg., 29: 35, 2003. 
8. DEL POZO, J.; FONSECA, E.: "Port-wine stain nodules in the adult: Report of 20 cases treated by $\mathrm{CO} 2$ laser vaporization". Dermatol. Surg., 27: 699, 2001.

*9. BOIXEDA, P.; PÉREZ-RODRÍGUEZ, M.; FERNÁNDEZ-LORENTE, M. y cols.: "Novedades en el láser cutáneo". Piel, 94: 199, 2003.

10. OWDHURY, M.M.; HARRIS, S.; LANIGAN, S.W.: "Potassium titanyl phosphate laser treatment of resistant port-wine stain". Br. J. Dermatol., 144: 814, 2001.

11. CORBI, R.; SÁNCHEZ, J.: "Láser de CO2 en patología genital". Piel, 13: 262, 1998.

12. VELÁSQUEZ, E.F.; CUBILLA, A.L.: "Lichen sclerosus in 68 patients with squamous cell carcinoma of the penis: Frequent atypias and correlation with special carcinoma variants suggest a precancerous role". Am. J. Surg. Pathol., 27: 1448, 2003.

13. ÁLVAREZ, C.; MEIJIDE, F.; RODRÍGUEZ, L. y cols.: "Carcinoma verrucoso de pene desarrollado sobre un liquen plano. ¿Una autentica lesión preneoplásica?”. Actas Urol. Esp., 30: 90, 2006.

14. HREBINKO, R.L.: "Circumferencial laser vaporization for severe meatal stenosis secondary to balanitis xerotica obliterans". J. Urol., 156: 1735, 1996.

*15. HUGUET, J.; ERRANDO, C.; REGALADO, R. y cols.: "Urethral condyloma in the male: Experience with 48 cases". Arch. Esp. Urol., 49: 675, 1996.

16. ZAAK, A.; HOFSTETTER, A.; FRIMBERGER, D. y cols.: "Recurrence of condyloma acuminata of the urethra after conventional and fluorescence controlled NdYAG laser treatment". Urology, 61:1011, 2003.

17. BEUTNER, K.R.; FERENCZY, A.: "Therapeutic approaches to genital warts". Am. J. Med., 102: 28, 1997.

18. McKENNA, J.G.; McMILLAN, A.: "Management of intrameatal warts in men”. Int. J. Std. AIDS, 1: 259, 1990.

19. LEVINE, L.A.; ELTERMAN, L.; RUKSTALIS, D.B.: "Treatment of subclinical intraurethral human papiloma virus infection with interferon alfa-2B". Urology, 47: 553, 1996.

20. MICALI, G.; NASCA, M.R.; INNOCENZI, D. y cols.: "Penile cancer". J. Am. Acad. Dermatol., 54: 369, 2006.

*21. TEWARI, M.; KUMAR, M.; SHUKLA, H.S.: "NdYAG laser treatment of early stage carcinoma of the penis preserves form and function of penis". Asian $\mathrm{J}$. Surg., 30: 126, 2007.

22. CUEVAS, J.; DE EUSEBIO, E.; DÍEZ, E. y cols.: "Cirugía de Mohs: Aplicación de la técnica a neoplasias del pene". Actas Urol. Esp., 31: 1076, 2007.

23. FRIMBERGER, D.; HUNGERHUBER, E.; ZAAK, D. y cols.: "Penile carcinoma. Is Nd-YAG laser therapy radical enough?". J. Urol., 168: 2418, 2002.

*24. VAN BEZOOIJEN, B.P.J.; HORENBLAS, S.; MEINHARDT, W. y cols.: "Laser therapy for carcinoma in situ of the penis". J. Urol., 166: 1670, 2001.

25. WEESE, D.; MURPHY, J.; ZIMMERN, P.E.: "NdYAG treatment of extramammary Paget's disease of the penis and scrotum". J. d'Urol., 99: 269, 1993.

26. MALLOY, T.R.: "External genitalia". Lasers Urol. Surg., 3: 32, 1994

27. MARTÍNEZ, J.; MARTÍNEZ, M.; CEBRIÁN, C. y cols.: "Hemangioma cavernoso de pene". Actas Urol. Esp., 25: 589, 2001.

28. DEHNER, L.P.; SMITH, B.H.: "Soft tissue tumors of the penis. A clinicopathologic study of 46 cases". Cancer,25: $1431,1970$.

29. ASHINOFF, R.; GERONEMUS, R.G.: "Flashlamppumped dye laser for port wine stains in infancy: Earlier versus later treatment". J. Am. Acad. Dermatol., 24: 467,1991
30. POETKE, M.; PHILIPP, C.; BERLIEN, H.P.: "Treatment of hemangiomas in infancy and childhood with the flash lamppumped dye laser: Cutaneous versus mixed cutaneous-subcutaneous hemangiomas". Hautarzt, 52: 120, 2001.

31. SEVILA, A.; BOTELLA-ESTRADA, R.; NAGORE, E. y cols.: "Valoración del tratamiento de los hemangiomas infantiles ulcerados".Actas Dermosifiliogr., 93: 340, 2002.

32. CHICOTE, F.; BORRELL, A.; ALCALÁ-SANTAELLA, C. y cols.: "Angioma tuberosos del glande del pene: Tratamiento con láser y anestesia local". Actas Urol. Esp., 24: 265, 2000.

33. RAULIN, C.; GREVE, B.: "Retrospective clinical comparison of hemangioma treatment by flashlamppumped $(585 \mathrm{~nm})$ and frequency-doubled $\mathrm{Nd}$ : YAG (532 nm) lasers". Laser Surg. Med., 28: 40, 2001.

34. SÁNCHEZ-CARPINTERO, I.; MIHM, M.C.; MIZERACKI, A. y cols.: "Epithelial and mesenchymal hamartomatous changes in a mature port-wine stain: Morphologic evidence for a multiple germ layer field defect". J. Am. Acad. Dermatol., 50: 608, 2004.

35. KOSTER, P.H.; VAN DER HORST, C.M. y cols.: "Histologic evaluation of skin damage after overlapping and nonoverlapping flashlamp pumped pulsed dye laser pulses: A study on normal human skin as a model for port wine stains". Laser Surg. Med., 28: 176, 2001.

36. LAPIDOTH, M.; AD-EL, D.; DAVID, M. y cols.: "Treatment of angiokeratoma of fordyce with pulsed dye laser". Dermatol. Surg., 32: 1147, 2006.

37. ANTONY, F.; MORTIMER, P.S.; HARLAND, C.C.: "Acquired scrotal lymphangiomas: Successful treatment with cutting diathermy and carbón dioxide laser". Clin. Exp. Dermatol., 27: 192, 2002.

38. STRATIGOS, A.; DOVER, J.S.; ARNDT, K.A.: "Laser treatment of pigmented lesions-2000: How far have we gone?". Arch. Dermatol., 136: 915, 2000.

39. SPICER, M.S.; GOLDBERG, D.J.: "Lasers in dermatology". J. Am. Acad. Dermatol., 34: 1, 1996.

40. KILMER, S.L.; WHEELAND, R.G.; GOLDBERG, D.J. y cols.: "Treatment of epidermal pigmented lesions with the frequency-doubled Q-switched Nd: YAG laser: A controlled, single-impact, dose-response, multicenter trial". Arch. Dermatol., 130: 1515, 1994.

41. SUH, D.H.; HAN, K.H.; CHUNG, J.H.: "The use of Qswitched Nd: YAG laser in the treatment of superficial pigmented lesions in Koreans”. J. Dermatolog. Treat., 12: $91,2001$.

42. HOHENLEUTNER, U.; WLOTZKE, U.; KONZ, B. y cols.: "Carbon dioxide laser therapy of a widespread epidermal nevus". Laser Surg. Med., 16: 288, 1995.

43. BOYCE, S.; ALSTER, T.S.: "CO2 laser treatment of epidermal nevi: Long-term success". Dermatol. Surg., 28: 611, 2002.

44. KEN-ICHIRO, K.; HISANO, A.; YOSHITAKA, F.: "An analysis of 300 patients with congenital pigmented nevus who underwent laser treatment and a proposal of serial treatment-Osaka procedure". Laser Surg. Med., 9: 55, 1997.

45. GOLDMAN, M.P.; FITZPATRICK, R.E.; SATUR, N.M. y cols.: "Treatment of congenital and acquired pigmented nevi with the Q-switched alexandrite, ruby, YAG, and pigmented lesión lasers". Laser Surg. Med., 7: 48, 1995.

46. FRANCO DE CASTRO, A.; TRUHÁN, D.; CARRETERO, P. y cols.: "Fotocoagulación con láser de NdYAG de quistes sebáceos escrotales". Actas Urol. Esp., 26: 121, 2002. 